\title{
Aluminum Hydroxide Impurities Occlusions and Contamination Sources
}

\author{
GHEORGHE DOBRA ${ }^{1}$, SANTIAGO GARCIA-GRANDA ${ }^{2}$, SORIN ILIEV ${ }^{1}$, LUCIAN COTET ${ }^{1}$, \\ HULKA IOSIF ${ }^{3}$, PETRU NEGREA ${ }^{3}$, NARCIS DUTEANU ${ }^{3}$, ALINA BOIANGIU ${ }^{1}$, \\ LAURENTIU FILIPESCU ${ }^{4 *}$ \\ ${ }^{1}$ Alum SA Tulcea, 82 Isaccei Str. 820228, Tulcea, Romania \\ ${ }^{2}$ University of Oviedo, Department of Physical and Analytical Chemistry, C/Julian Clavria 8, 33006 Oviedo \\ ${ }^{3}$ University Politehnica Timisoara, Faculty of Industrial Chemistry and Environmental Engineering, 2 Piata Victoriei, \\ 300006, Timisoara, Romania \\ ${ }^{4}$ University Politehnica of Bucharest, Faculty of Applied Chemistry and Materials Science, Analytical Chemistry and \\ Environmental Engineering Department, 1-7 Gheorghe Polizu Str., 011061, Bucharest, Romania
}

\begin{abstract}
This paper is reporting the data concerning impurities occlusion in the dried, milled and classified aluminum hydroxide, the sources of contamination and the ways to control the purity of classified aluminum hydroxide as raw material for special aluminas. Mainly, all the micronic size particles, floating in the super-saturated Bayer liquors, are potential sources of occluded impurities in the aluminum hydroxide particles. There are several mechanisms for embedding the impurities in crystalline substances. Of these, most probable ones in the Bayer alumina process are: a) occlusion of the spent liquor drops containing impurities inside the polycrystalline aluminum hydroxide congregates; b) hetero-nucleation of aluminum hydroxide on the surface of particles or colloids containing one or more impurities (the foreign particles are seized inside a crystals or inside of a crystalline multiparticulate association); c) incorporation of available ions or molecule reactive fragments in the poor crystalline structures of aluminum hydroxide after nucleation, during different growth stages of all already aggregated particles, under certain super-saturations. $d$ ) building up bridges between the scanty aggregated particles or filling the inside hollows of these aggregates with new quickly crystallized material, including the particulate impurities, mainly, during large fluctuations of the super-saturation. Using scanning electron microscopy (SEM) coupled with energy dispersive X-ray spectroscopy EDS (Apollo SSD detector, EDAX), the contributions of each of these mechanisms can be investigated simply and assumed from the collected data. It was shown that well crystallized phases originating directly from bauxite (like the aluminum substituted goethite and substituted hematite, rutile or quartz), as well as the well as the crystallized new born phases during specific Bayer reactions (like cancrinite, are not promoting directly the impurities occlusion. Poor crystalline phases (like sodalite and katoite or other secondary phases and their micronic size fragments are really sustaining impurities occlusion through all the acknowledged mechanisms.
\end{abstract}

Keywords; alumina hydrate, bauxite residue, impurities, mineralogical phases, occlusion, microscopy

\section{Introduction}

It is well known that in the pure substances technology, there is easier and cheaper to purify the raw materials, from which a certain product of advanced purity is manufactured, instead to purify it after synthesis or after its manufacture from raw materials of questionable quality. For this reason, the manufacturing process of aluminum hydroxide (hydrate, hydrated alumina) of advanced purity, as a future raw material for production of special aluminas, starts with the investigation of available raw materials purity. In this framework, at Vimetco Alum SA Tulcea, the main efforts for obtaining a pure aluminum hydroxide were focused on: a) investigation of ways to raise the quality of bauxite residue (BR) to allow its complete separation from sodium aluminate liquors (by settling, washing and press filtation), providing future options to avoid the contamination of strong liquors with insoluble

*email: laurentiu_filipescu@yahoo.co.uk 
components of submicronic sizes, emerging from both bauxite phases and new born cristalline (or amorphous) phases in Bayer technology; b) Investigation of the ways to improve the quality of crystallized tricalcium aluminate (TCA), used for depth filtration and ultrafiltration of the strong liquors of sodium aluminate (from which crystallizes aluminum hydroxide) on a layer of TCA; c) overhauling the deep filtration unit of sodium aluminate strong liquors on a TCA layer and introducing some new high-performance equipments, which secure an advanced degree of purity for this raw material of primary importance in the manufacture of pure aluminum hydroxide; d) Investigation the nature and concentration of organic substances in the concentrated sodium aluminate liquors, in order to identify ways to eliminate these soluble compounds from sodium aluminate liquors, as well as the ways to limit the accumulation of organic impurities, which are carrying bound sodium as impurity in the aluminum hydroxide (hydrate, hydrated alumina) particles. The purpose of this work is to investigate the crystallinity and "patterns" of impurities occlusion in the aluminum hydroxide particles, mainly by entrapping the crystalline or amorphous fragments from the bauxite residue, originating both from the bauxite mineralogical phases and from the new mineralogical phases born in the Bayer technology. The comprehension of the occlusion mechanism is useful for better control of the physical and chemical processes during of bauxite residue formation and its separation from the liquid phase. Also, the awareness of occlusion mechanism provide efficient choices for the aluminum hydroxide crystallization process parameters, aiming to prevent the contamination of concentrated liquors of sodium aluminate (raw material for the manufacture of aluminum hydroxide) with liquid-phase soluble impurities (ionic substances) [1] or with insoluble impurities such as solid phases (crystalline or amorphous substances of an organic or inorganic nature) associated with micronic size particles of all mineralogical components from the bauxite residue [2-4]. More precisely, the present study aims to re-evaluate the parameters of the aluminum hydroxide precipitation technology in order to prevent the occlusion of impurities in the aluminum hydroxide used as a raw material for special aluminas. This paper is the result of a technical and scientific collaboration between Vimetco Alum SA Tulcea, Romania, University of Oviedo-CINN, Spain and University Politehnica of Timisoara.

\section{Materials and methods}

\subsection{Sample preparation}

Samples of aluminum hydroxide were collected from the third test of the new unit designed for production new sorts of special dried, milled and classified aluminum hydroxide, as part of the European project: "Endow the Research \& Development Department of SC ALUM SA with independent and efficient research facilities to support the economic competitiveness and business development (Financing Contract nr.64/08.09.2016, ID: P_34_286, Cod SMIS: 103867). Firstly, during the experiments, samples of the milled and non milled aluminum hydroxide were collected in a few rounds. Then, from these materials, there were separated representative specimens for each size dimension class. In the Figure 1 there are shown the particle size distribution of both milled and non milled aluminum hydroxide. During the same period of time in a similar way there were collected representative specimens of bauxite residue, which were filtered and dried in air (up to $8 \%$ of free water). Part of these specimens were dried for $4 \mathrm{~h}$ at $105^{\circ} \mathrm{C}(0 \%$ free water). All kinds of specimens were used for mineralogical analysis and microscopically analysis.

\subsection{Mineralogical analysis}

Acquisition of data was achieved on the BRUKER D8 ADVANCE diffraction instrument by means of the DIFFRAC plus XRD Commander (Bruker AXS) software through the Bragg-Brentano diffraction method, coupling $\Theta-\Theta$ on vertical configuration. The data processing was performed by means of the DIFFRAC plus BASIC Evaluation Package software, version EVA12, 2006 of the software package containing DIFFRAC plus BASIC (Bruker AXS) and the data base ICDD PDF-2 Released 2006. Other details were given elsewhere [5]. 


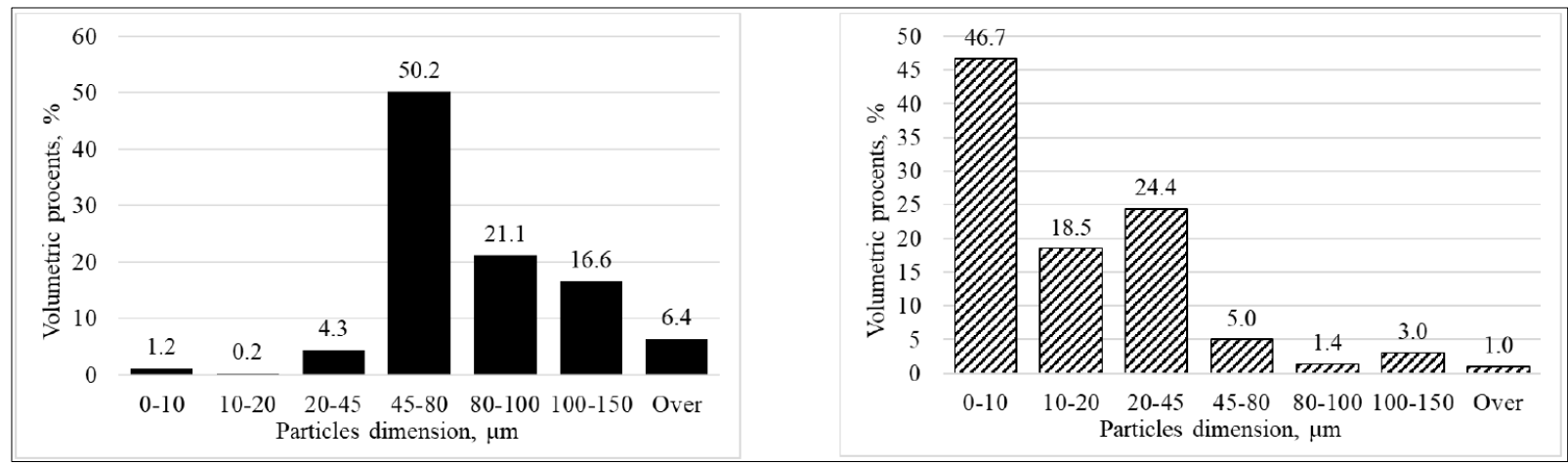

Figure 1. Particle size distribution (PSD) of the aluminum hydroxide before milling (left) and after milling (right)

\subsection{Microscopically analysis}

The morphology and elemental composition of the particulate material samples (bauxite, bauxite residue and aluminum hydroxide) was characterized by scanning electron microscopy (SEM: Quanta FEG 250, FEI, The Netherlands) using back scattered electron detector (BSD) coupled with energy dispersive X-ray spectroscopy (EDS: using Apollo SSD detector, EDAX Inc. US). The microstructure and ED's analysis were performed at about $10 \mathrm{~mm}$ working distance (WD) in low vacuum mode in order to avoid surface charging and damage of the analyzed material.

\section{Results and discussions}

SEM microscopy coupled with EDX spectroscopy is an effective tool for detecting impurities in any natural material or manufactured by any technology. Furthermore, the method allows identification of the source and procedures to avoid contamination by controlling the technology in the right stage where the source is providing materials for contamination aluminum hydroxide particles. This ultimate advantage has led to the application of SEM microscopy coupled with EDX spectroscopy to the analysis of non milled and milled aluminum hydroxide samples [6]. The mechanism of contamination aluminum hydroxide with occluded impurities is simple and is taking place in correlation with three conditions coming from understanding the course of any crystallization process a) the presence of micron size particles in the supersaturated Bayer liquors due to the poor working of red filtration, and especially due to the poor quality of the filtering material - the freshly precipitated tricalcium aluminate; $b$ ) the fluctuation of supersaturation (control by the temperature-concentration relationship) in all stages of nucleation, agglomeration and growth of the particles in decomposition line of sodium aluminate, but especially, in the agglomeration stage; c) the crystallinity of the mineralogical phases and the share of amorphous particles fraction in the small size bauxite residue particles, conveyed by super-concentrated liquors in the crystallizing vessels [7-13].

\subsection{The well-crystallized mineralogical phases from bauxite residue involved in occlusion contamination of the aluminum hydroxide}

Aluminum substituted goethite (Figure 2) is a well-crystallized phase coming directely from bauxite, without chemical changes during Bayer processing. Basically, this phase has no contribution to contamination of the aluminum hydroxide particles (surface tied or by occlusion). Fine oxalate, aluminate, carbonate and silicate particles of sodium, calcium and magnesium adhere to surface of the aluminum substituted goethite particle. The mass of these impurities is insignificant when compare with the mass of aluminum substituted goethite particle, but it matters enormously when these particles act as heteronuclei and are embedded in the particles of aluminum hydroxide. Figure 3 represents a relatively pure aluminum substituted hematite particle of class $50100 \mu \mathrm{m}$, surrounded by small particles carrying other impurities. Among these particles is a gibbsite particle (according to the concentrations table, next to the figure, showing the atomic concentrations measured at a point on the surface of the pure aluminum 
substituted hematite crystal). Its origine is also, the bauxite, without chemical changes during Bayer processing.
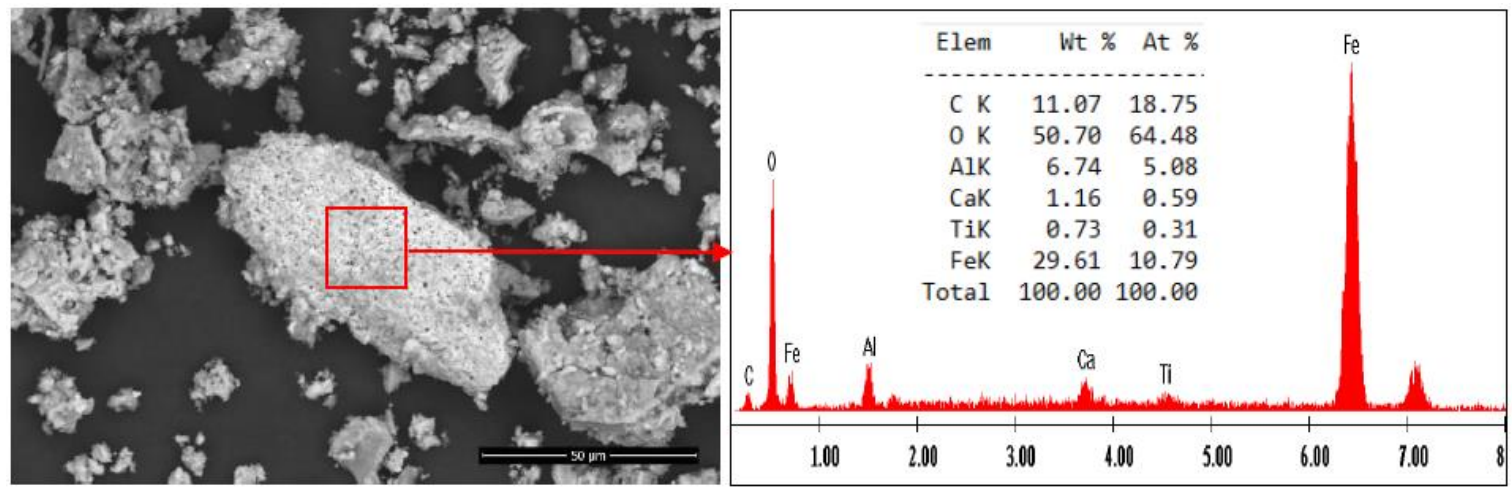

Figure 2. Morphology of an aluminum substituted goethite $\left[\left(\mathrm{Fe}_{\mathrm{x}} \mathrm{Al}_{(\mathrm{I}-\mathrm{x})} \mathrm{O}(\mathrm{OH})\right]\right.$ particle, collected from the dried BR at $105^{\circ} \mathrm{C}$, investigated by diffraction EDS on a surface of $20 \mu \mathrm{m}^{2}$ and magnification 2500x. SEM image of a well crystallized aluminum substituted goethite particle from PSD class bellow $100 \mu \mathrm{m}$, with $\mathrm{TiO}_{2}$ occlusions and contaminated with calcium salts (probably, carbonates, aluminates, oxalate and formiate). Actual formula of this compound in Sierra Leone bauxite is

$\left(\mathrm{Fe}_{0.7768 \pm 0.0021} \mathrm{Al}_{0.2232 \pm 0.0021}\right) \mathrm{O}(\mathrm{OH})$
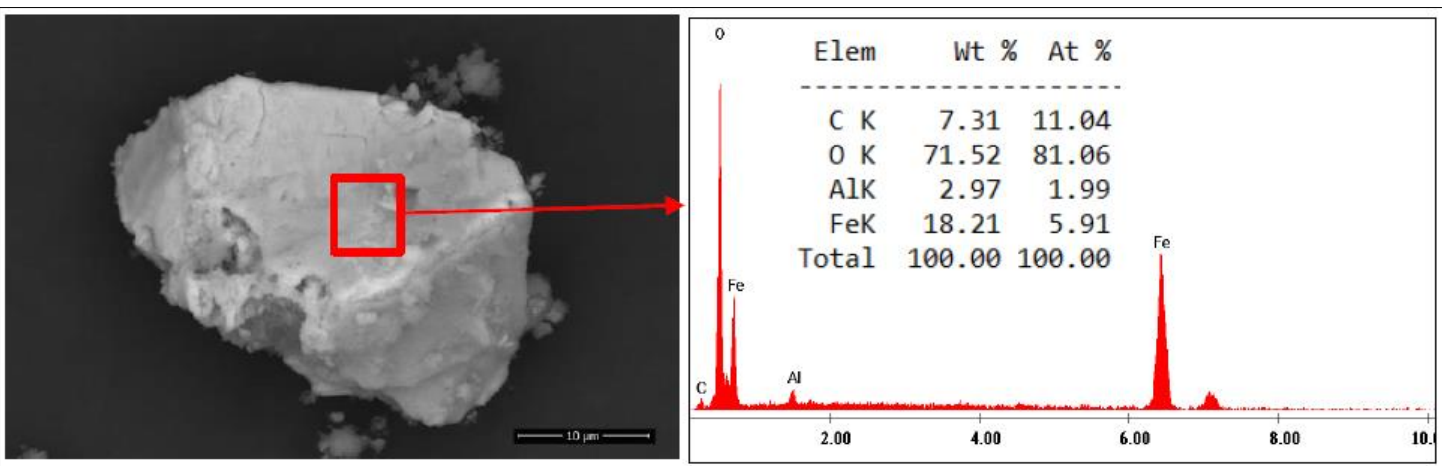

Figure 3. Morphology of an aluminum substituted hematite $\left(\mathrm{Fe}_{2-\mathrm{x}} \mathrm{Al}_{\mathrm{x}} \mathrm{O}_{3}\right)$ particle, collected from the dried BR at $105^{\circ} \mathrm{C}$, investigated by diffraction EDS on a surface of about $5 \mu \mathrm{m}^{2}$ and magnification 8000x. SEM image of a well crystallized aluminum substituted hematite particle from PSD below

$50 \mu \mathrm{m}$, with very clean surface. Actual formula of this compound in Sierra Leone bauxite is

$\left(\mathrm{Fe}_{0.9294 \pm 0.0031} \mathrm{Al}_{0.0706 \pm 0.0031}\right)_{2} \mathrm{O}_{3}$
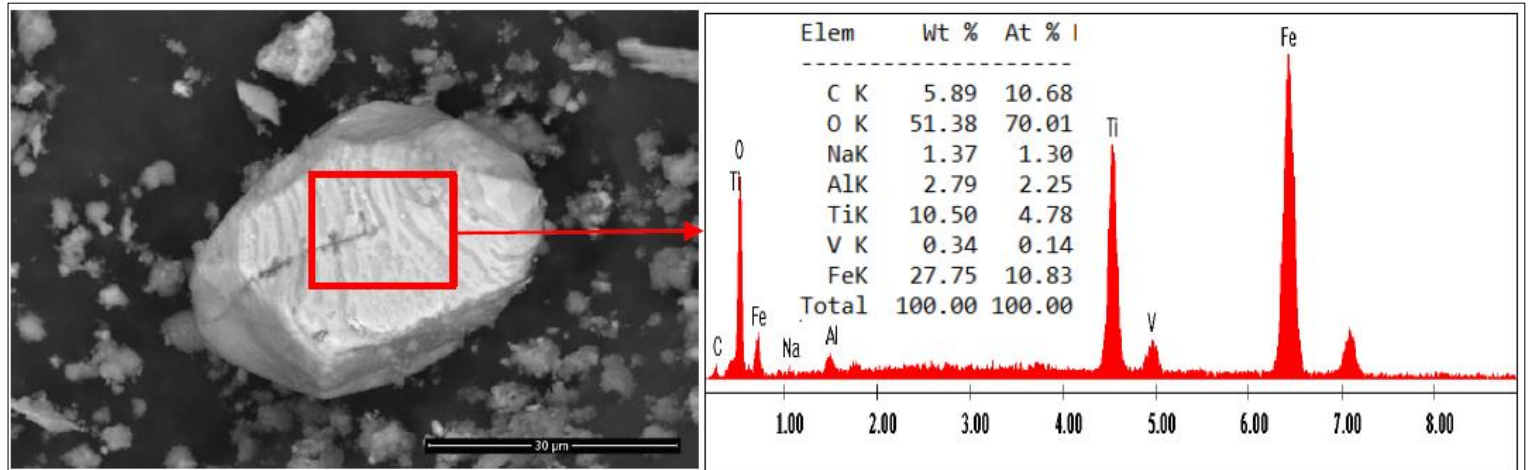

Figure 4. Morphology of an ilmenite $\left(\mathrm{FeH}_{6} \mathrm{O}_{3} \mathrm{Ti}\right.$ or $\left.\mathrm{FeTiO}_{3}\right)$, particle, collected from dried $\mathrm{BR}$ at $105^{\circ} \mathrm{C}$, investigated by diffraction EDS on a surface of $15 \mu \mathrm{m}^{2}$ and magnification $8000 \mathrm{x}$. SEM image

of a well crystallized ilmenite particle from PSD class bellow $50 \mu \mathrm{m}$, in which ilmenite it is incorporated in a mass of aluminum substituted hematite and contaminated with sodium and vanadium 
Figure 4 shows well-crystallized ilmenite and aluminum substituted hematite, with the surface contaminated by compounds of sodium, iron, aluminum and vanadium. All these impurities come from the Bayer liquors and are tied to surface of the ilmenite crystal by adsorption. Large ilmenite crystals (around $30 \mu \mathrm{m}$ ) are found with high frequency in the bauxite residue and originate, as well as aluminum substituted goethite and aluminum substituted hematite, certainly from bauxite. Chiefly, ilmenite is not or should not be an occlusion promoter, due to the high mechanical stability of its particles.
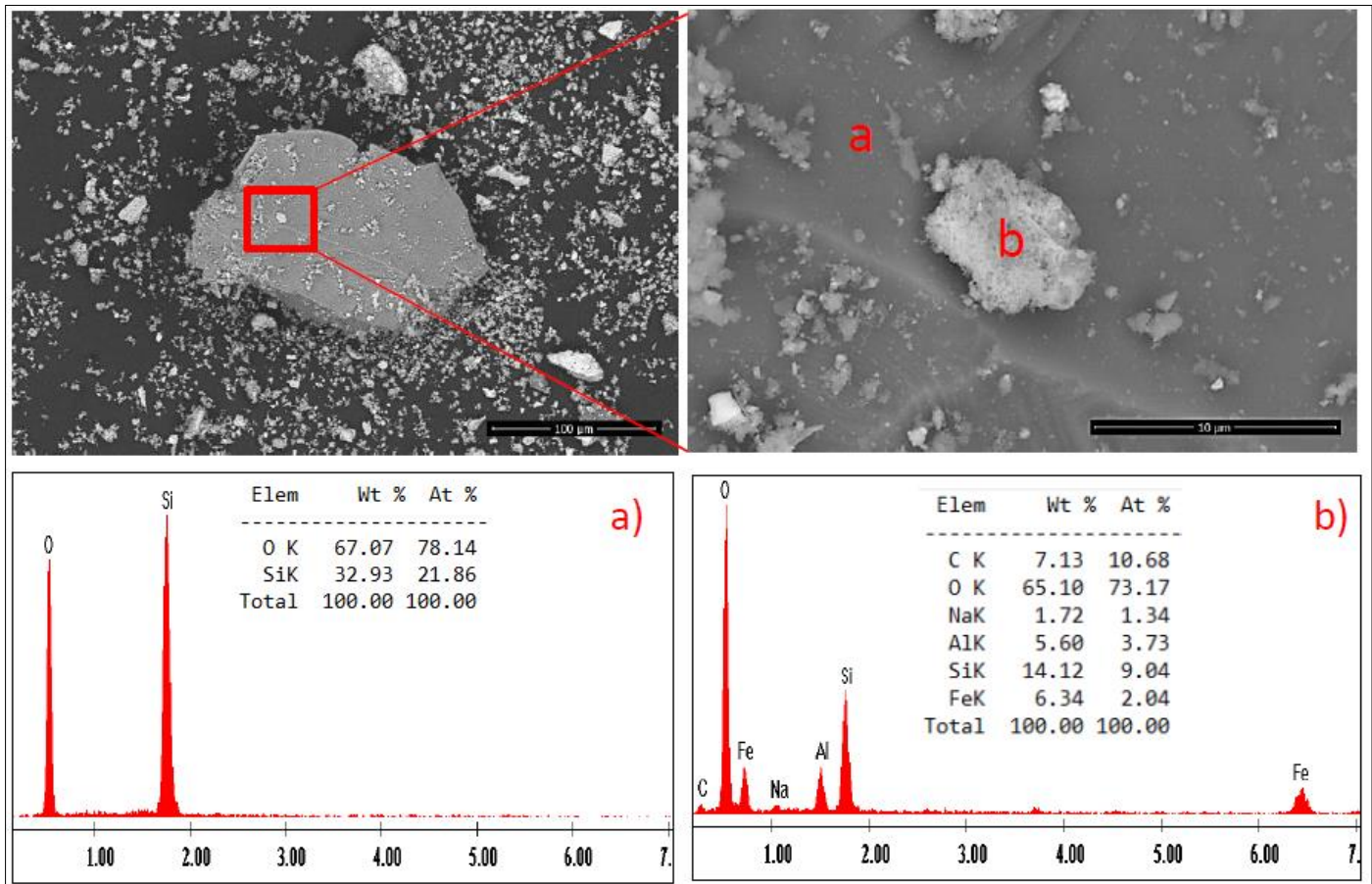

Figure 5. Morphology of an agglomerated silica-sodalite large particle, collected from dried BR at $105^{\circ} \mathrm{C}$, investigated by diffraction EDS on a surface of $5 \mu \mathrm{m}^{2}$ and magnification 1000x. SEM image of a small compact surface of a large unit originating from PSD class over $100 \mu \mathrm{m}$ a) Pure quartz as main component of the particle; b) sodalite, quartz and aluminum substituted hematite or goethite
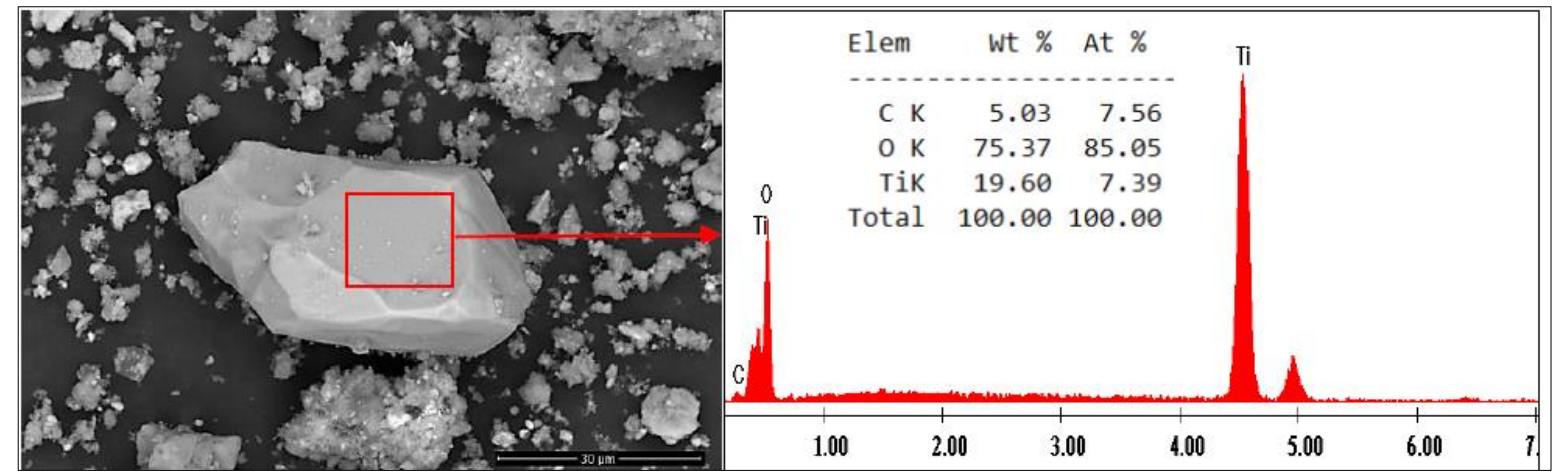

Figure 6. Morphology of well crystallized rutile $\left(\mathrm{TiO}_{2}\right)$ particle collected from dried $\mathrm{BR}$ at $105^{\circ} \mathrm{C}$, investigated diffraction EDS on a surface of $15 \mu \mathrm{m}^{2}$ and magnification of 2500x. SEM image 0f a well crystallized rutile particle from PSD class bellow $50 \mu \mathrm{m}$ with clean rounded surfaces

Quartz (Figure 5) is definitely originating from bauxite as part of non-reactive silica fraction. As a component of bauxite residue, the quartz is certainly not an occlusion promoter, but it could be a carrier for other poor crystallized components, which are doubtless occlusion promoters. A large particle of quartz is presented in the Figure 5. Around the large particle and tied on the clear crystalline face, there 
are fine particles containing other components. One of these is a particle of sodalite, as poor crystallized mineralogical phase, which, as free particle, is an occlusion promoter when is floating in the concentrated Bayer liquors.

Rutile is another well crystallized component in the bauxite residue, coming chemically unchanged from bauxite (Figure 6). Its surface is smooth and clean (does not absorb ionic impurities). As the other well crystallized phases, this compound cannot trigger contamination by occlusion in the concentrated Bayer liquors.

All the crystalline phases presented above are typical mineralogical phases of the bauxite residue. These phases are not generated in the Bayer process. They entirely originate from bauxite. Only the accompanying small size particles, produced in Bayer process, are the plausible contaminants by occlusion, but barely when they occur to be in super-saturated Bayer liquors.

\subsection{The poor-crystallized mineralogical phases from bauxite residue involved in contaminations by occlusion of the aluminum hydroxide}

The mineralogical phases formed during the Bayer process are: gibbsite (present in the bauxite residue accidentally, as a technological loss), sodalite, cancrinite and katoite, all as phases with fluctuating crystallinity. The contamination and technological losses in aluminum hydroxide are proportional with the share of these conglomerates in the mass of the bauxite residue. Clearly, these residual phases range in the concentrated Bayer liquors from small size, well-formed crystals to small size crystalline and amorphous conglomerates.

Figure 7 shows the crystalline / amorphous conglomerates with the typical structure of sodalite. The conglomerate in the central part of the figure certainly contains semi-crystallized sodalite, along with other phases such as quartz, aluminum substituted goethite and aluminum substituted hematite (as well crystallized phases), and cancrinite and katoite (as poor crystallized phases), also identified in some other analyzed samples. A little piece, outside the central conglomerate, is the pure sodalite. Carbon concentration in this sample is very high, may be due to the preferentialy adsorption of the organic compounds on larger surfaces available on any of the agglomerated particles. But, formation of sodium and calcium salts with organic compounds, as particulate materials, cannot be excluded. In this case, such small size semi-crystalline particles are exhibiting large heterogenous surfaces, able to initiate occlusions, even at minute super-saturations. Concernig the given formula of sodalite, it should be mentioned that the chlorine in analyzed products was replaced in most of the cases by carbonate and sulphate. Just few times there was found the chlorine in bauxite residue (BR).

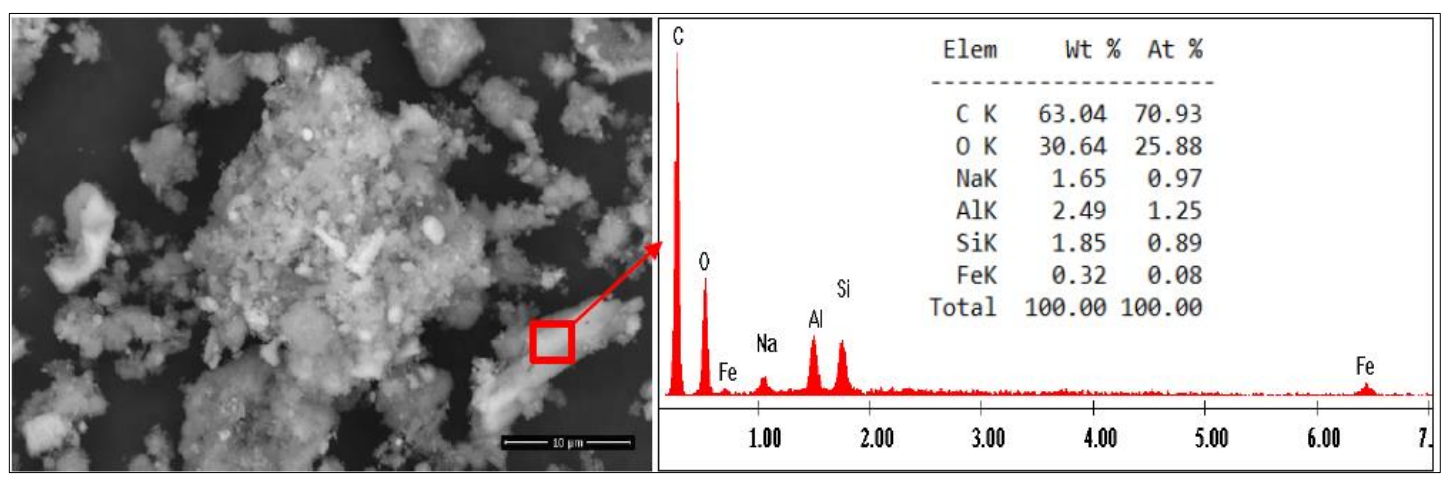

Figure 7. Morphology of a sodalite $\left(\mathrm{Na}_{8} \mathrm{Al}_{6} \mathrm{Si}_{6} \mathrm{O}_{24} \mathrm{Cl}_{2}\right.$ or $\left.\mathrm{Na}_{4}\left(\mathrm{Si}_{3} \mathrm{Al}_{3}\right) \mathrm{O}_{12} \mathrm{Cl}\right)$ particle, collected from dried $\mathrm{BR}$ at $105^{\circ} \mathrm{C}$, investigated by diffraction EDS on a surface of $2 \mu \mathrm{m}^{2}$ and magnification 8000x;

SEM image of a poor crystallized sodalite particle from PSD class bellow $20 \mu \mathrm{m}$, with some other crystalline phases (other than $\mathrm{Al}_{2} \mathrm{O}_{3}$ and $\mathrm{Fe}_{2} \mathrm{O}_{3}$ phases) bonded on its surface

Cancrinite (Figure 8), as mineral, is a compund with the chemical formula similar with the above presented one for sodalite. When slaked lime is added in Bayer liquors before digestion, calcium replaces 
partially the sodium and the cancrinte crystallizes beside unconverted sodalite. Usually, this conversion is just partial and in the most of the cases the both phases are found togethter. Calcium is added at a given ratio, enough to crystaleze a mixture with rezonable filtrability

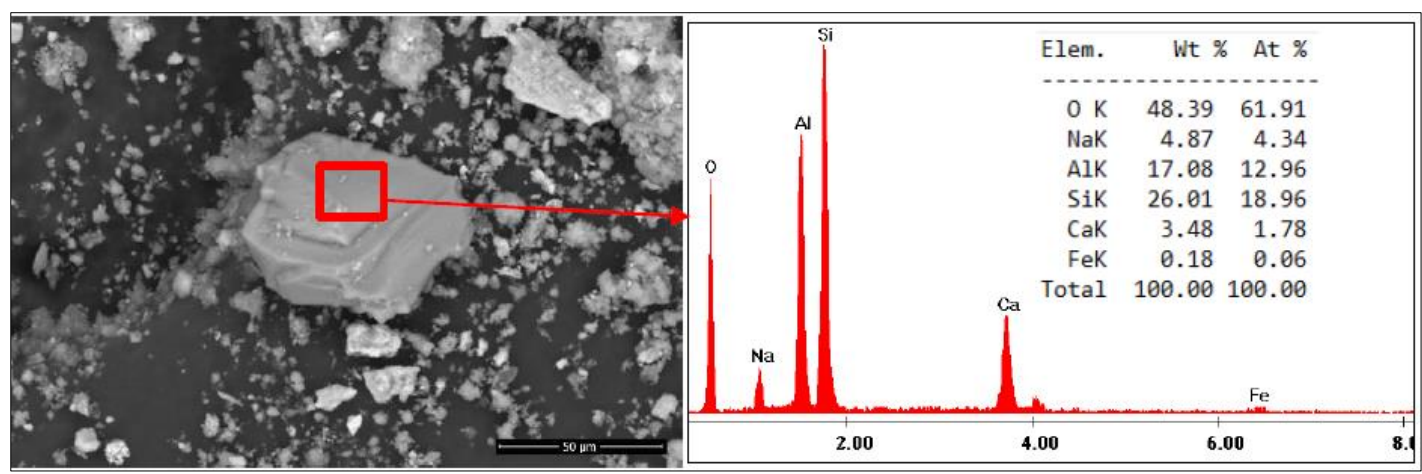

Figure 8. Morphology of a cancrinite $\left(\mathrm{Na}_{6} \mathrm{Ca}_{2} \mathrm{Al}_{6} \mathrm{Si}_{6} \mathrm{O}_{24}\left(\mathrm{CO}_{3}\right)_{2}\right)$ - sodalite mixture particle, collected from dried BR at $105^{\circ} \mathrm{C}$, investigated by diffraction EDS on a surface of $20 \mu \mathrm{m}^{2}$ and magnification 2000x. SEM image of a well crystallized material containing both phases coming from PSD class bellow $50 \mu \mathrm{m}$, with $\mathrm{Fe}_{2} \mathrm{O}_{3}$ inclusions

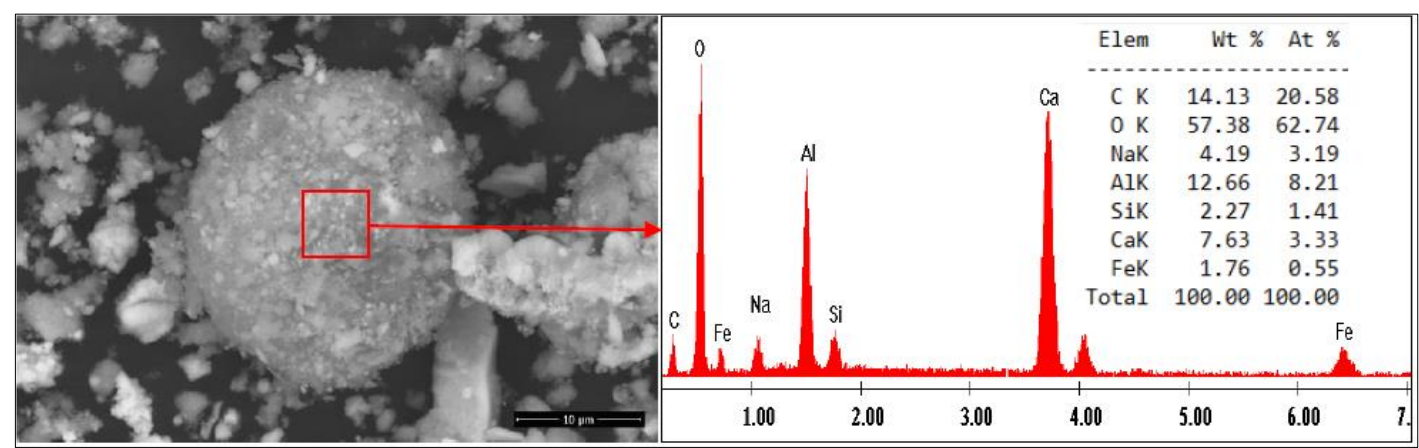

Figure 9. Morphology of a cancrinite-katoite $\left[\left(\mathrm{Ca}_{3} \mathrm{Al}_{2}\left(\mathrm{SiO}_{4}\right)_{3-\mathrm{x}}(\mathrm{OH})_{4 \mathrm{x}}\right.\right.$ where $\left.\left.\mathrm{x}=1.5-3.0\right)\right]$ particle,

collected from dried BR at $105^{\circ} \mathrm{C}$ investigated by diffraction EDS on a surface of $5 \mu \mathrm{m}^{2}$ and magnification 8000x. SEM image of a crystallized agglomerated particle from PSD class bellow 50 $\mu \mathrm{m}$, with $\mathrm{Fe}_{2} \mathrm{O}_{3}$ inclusions

Figure 8 shows a typical cancrinite crystal $\left\{\mathrm{Na}_{6} \mathrm{Ca}_{2}\left[\left(\mathrm{CO}_{3}\right)_{2} \mid \mathrm{Al}_{6} \mathrm{Si}_{6} \mathrm{O}_{24}\right] \cdot 2 \mathrm{H}_{2} \mathrm{O}\right\}$ containing some unconverted sodalite. The central crystal is surrounded by micronic size particles with various compositions. Due to the ordered crystalline structure, the cancrinite produces fewer micro-crystals capable to promote the contamination of aluminum hydroxide by occlusion.

In the Figure 9 there are shown polycrystalline conglomerates with a complex structure and with dimensions of tens of microns. There are two properties of this type of associations:

- heterogeneous composition in which can be distinguished multiple particles containing different crystalline and amorphous phases;

- mechanical fragility of all aggregates, regardless of size and chemistry of each mineralogical phase. For the reasons listed above, these aggregates commonly generate micron size particles in the concentrated Bayer liquors as a permanent source of crystalline or amorphous impurities, prone for occlusion in the aluminum hydroxide particles.

In this part of the paper, there were examined the mineralogical phases which are generating fine particles and reactive fragments ready to trigger the occlusion in the aluminum hydroxide particles. The knowledge of mineralogical phases generating occluded impurities in Bayer alumina process, as well as their properties, is very important for identifying occlusion mechanisms and for engineering 
substantiation of the measures to prevent contamination of the dried, milled and classified aluminum hydroxide at Alum SA Tulcea, Romania.

\subsection{Occlusion of impurities as fine particles and reactive fragments in the aluminum hydroxide particles}

For improving quality of the EDAX analysis and for detection of possible unobservable occlusions, the carefully selected aluminum hydroxide particles were incorporated into a polymer recommended in the equipment book. The face exposed to microscopic analysis was polished before being placed in the sample chamber of the microscope. The second selection of the analyzed sample was made taking into account not only the clarity of image as in the previous experiments, but also the accuracy of measurements on deeper layers in mass of the particles. Final selection was made after collecting and processing the first images. This way to conduct spectral analysis of the samples excludes the carbon from the sum of the elements concentrations, due to carbon content in the used polymer. Thus the reading of results was much easier,

In the Figure 10 are shown two samples of very pure and not occluded aluminum hydroxide. These samples show the advanced purity of product (concentration of the impurities is found at the detection limit). Comparing these data with those evaluated from the measurements presented in previous images and in the Figures 11-13, it can be stated that the results obtained are more coherent and certainly more accurate
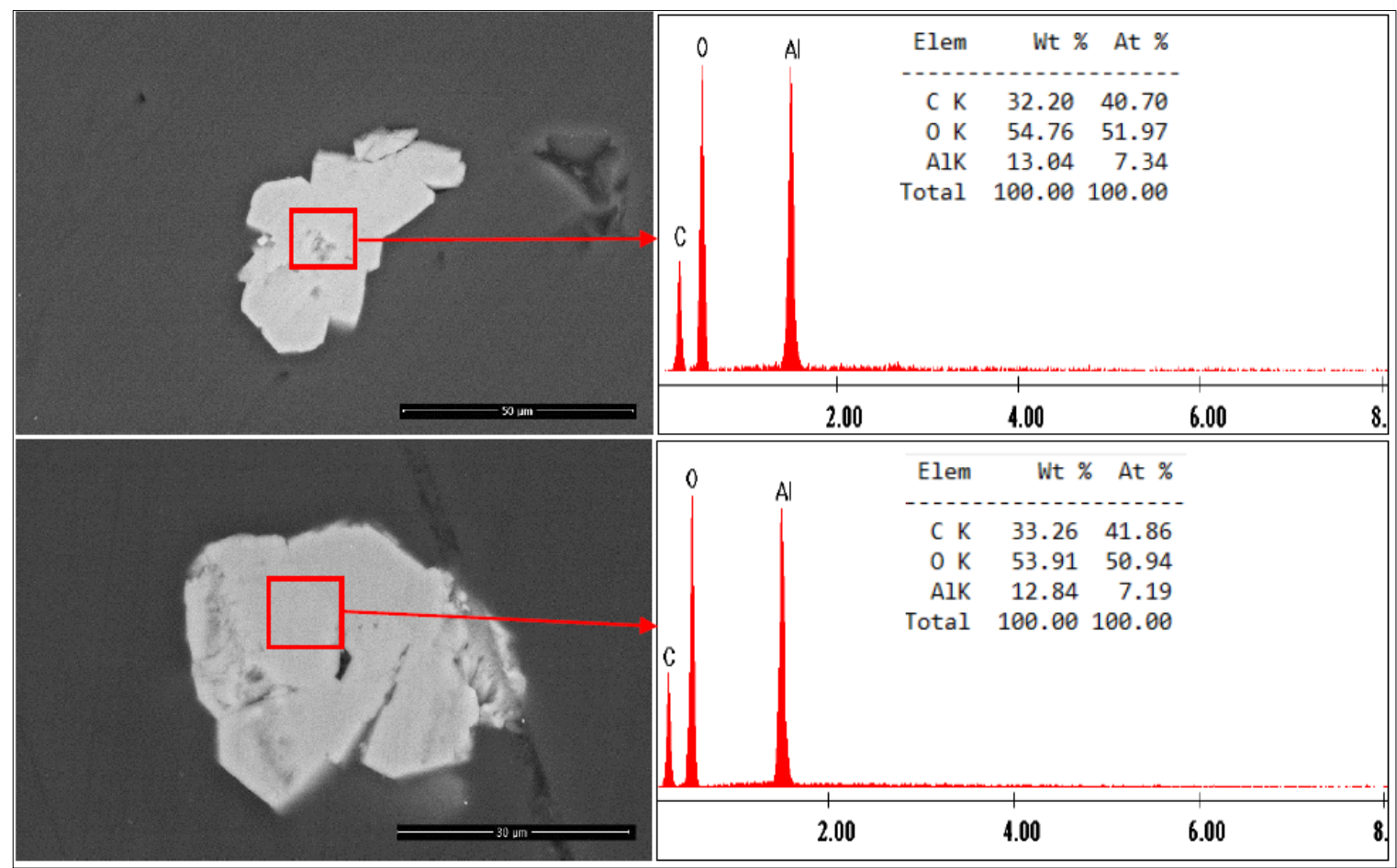

Figure 10. Two very pure aluminum hydroxide particles, collected from dried and classified product, investigated by diffraction EDS on a surface of $13 \mu \mathrm{m}^{2}$ (top) and $30 \mu \mathrm{m}^{2}$ (bottom), and magnification 3000x (top) and respectively, 5000x(bottom). SEM image of a well crystallized aluminum hydroxide particles from PSD class bellow $50 \mu \mathrm{m}$

At this point, it should be recalled, once again, that the purpose of this study was not to verify the purity of aluminum hydroxide, but only the occlusion mechanism and its causes. This is way the occlusion mechanism was investigated on a significant number of samples and specimens, randomly chosen during the experiments. 
Scanned particle in Figure 11 represents the occlusion of a fragment from a quartz particle $\left(\mathrm{SiO}_{2}\right)$ embedded in a larger particle of aluminum hydroxide. The particle size of silicon dioxide is less than 5 $\mu \mathrm{m}$ and the occluded particle less than $20 \mu \mathrm{m}$. The occluded phase is quartz with zero degree of contamination. The line in the carbon spectrum comes from the polymer in which the particle is embedded. This figure describes a typical occlusion produced by hetero-nucleation of aluminum hydroxide particles on the surface of small silica particles. At the same time the Figure 11 is a proof the hetero-nucleation shares a very significant part of the total number of occlusions. But, at the same time this type of contamination is hardly to be fully eliminated.

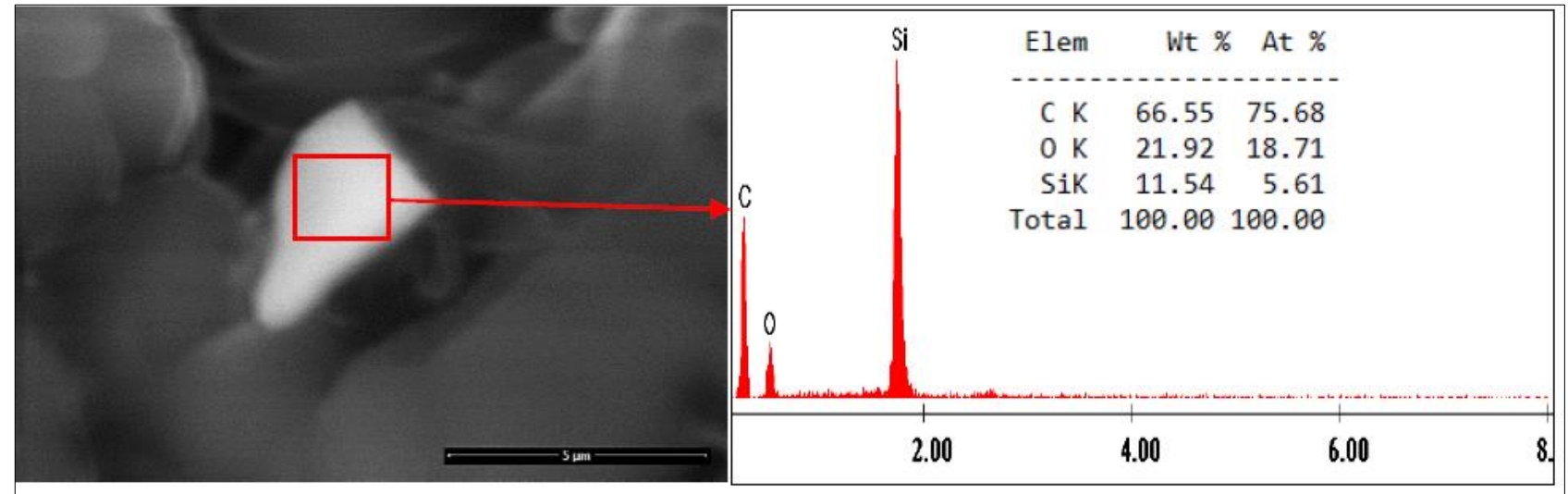

Figure 11. Morphology of an aluminum hydroxide particle, collected from dried and classified product, investigated by diffraction EDS on a surface of $2 \mu \mathrm{m}^{2}$ and magnification 30000x. SEM image of a well crystallized aluminum hydroxide particle from PSD class bellow $20 \mu \mathrm{m}$, with a quartz $\left(\mathrm{SiO}_{2}\right)$ occlusion (probably the heterogeneous surface able to trigger the nucleation of aluminum hydroxide)

Figure 12 shows a group of particles with maximum size dimension of $10 \mu \mathrm{m}$. In this group a minor contamination by occlusion with the ions sodium, magnesium and carbonates carbonate/ hydrocarbonates can be observed. Ultimately, the contamination might be just a surface adsorption or an occlusion with organic acids salts. In the points a) and c) the contamination degree is slightly higher than in the point b), but the noticed impurities are not relevant for a real occlusion. Actually, it is about a simultaneous uptake of the ions $\mathrm{Na}(1+), \mathrm{Mg}(2+)$ and $\mathrm{CO} 3(2-) / \mathrm{HCO} 3(1-)$ in the gibbsite crystalline lattice. This type of contamination is common and well known in all aluminum hydroxide production units. All over, this type of contamination is governed by the total alkalinity, expressed by the concentration by $\mathrm{Na}_{2} \mathrm{O}$ concentration and the $\mathrm{Na}_{2} \mathrm{O} / \mathrm{Al}_{2} \mathrm{O}_{3}$ ratio in all crystallization vessels along the entire line of sodium aluminates decomposition. This individual samples are the proofs of the minimal contaminations produced through this mechanism of occlusion,

Figure 13 shows another group of particles with a maximum particle size of $30 \mu \mathrm{m}$. The major phase in this group is a particle of contaminated aluminum hydroxide by significant occlusion with cancrinitesodalite, magnesium carbonate, rutile and additionaly traces of $\mathrm{K}$ and $\mathrm{V}$, as ions accompanying titanium. There is no mainly occluded phase in the analyzed fragment. It can be stated that the occluded impurities results from the breaking and dispersion in the mass of aluminum hydroxide of a polycrystalline aggregate of the type shown in the Figures 7 and 9. Minor surface contamination with vanadium, potassium and organic carbon is certain and has an impact over the purity of aluminum hydroxide. In other words, the individualized particle in the Figure 13 is a clear proof of a cancrinit-sodalite fragment occluded inside of aluminum hydroxide particle.

Examples presented above in the section 3.3, illustrate not only the mechanisms of impurities occlusion, but also reveal the sources of impurities. Thus, in each case, investigated and illustrated by the corresponding figure, there were indicated precisely: the contaminating phases (occluded phases) and impurities conveyed by them, and respectively, the contaminated phase, which is aluminum hydroxide particle collected from specified position in decomposition line. Also, for each particular case, 
the impurities occlusion mechanism was indicated: a) occlusion by incorporating fragments of welldefined mineralogical phases, b) ionic occlusion in the crystal lattice of gibbsite and/or the syncrystallization of impurities in crystalline state, and c) occlusion by hetero-nucleation, and all of them inside the mass of aggregates that form the architecture of aluminum hydroxide particle.
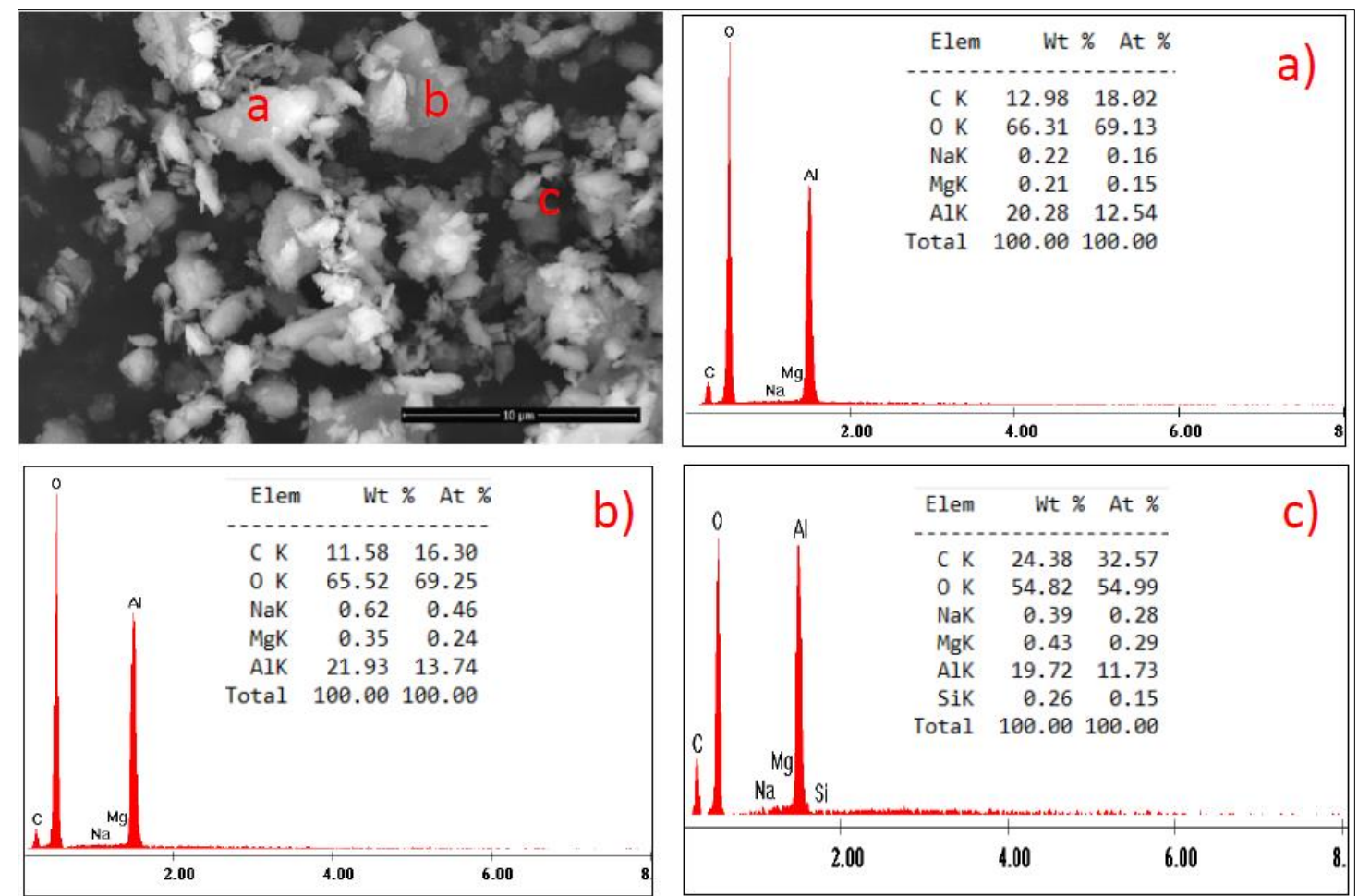

Figure 12. Morphology of the aluminum hydroxide particles, collected from dried and classified product, investigated by diffraction EDS on a surface of $2 \mu \mathrm{m}^{2}$ and magnification $15000 \mathrm{x}$. SEM images of the well crystallized aluminum hydroxide particles from PSD class bellow $10 \mu \mathrm{m}$, with: a) and b) sodium and magnesium occluded (probably, carbonates, aluminates, oxalates and formiate); c) sodium, magnesium and silica occluded
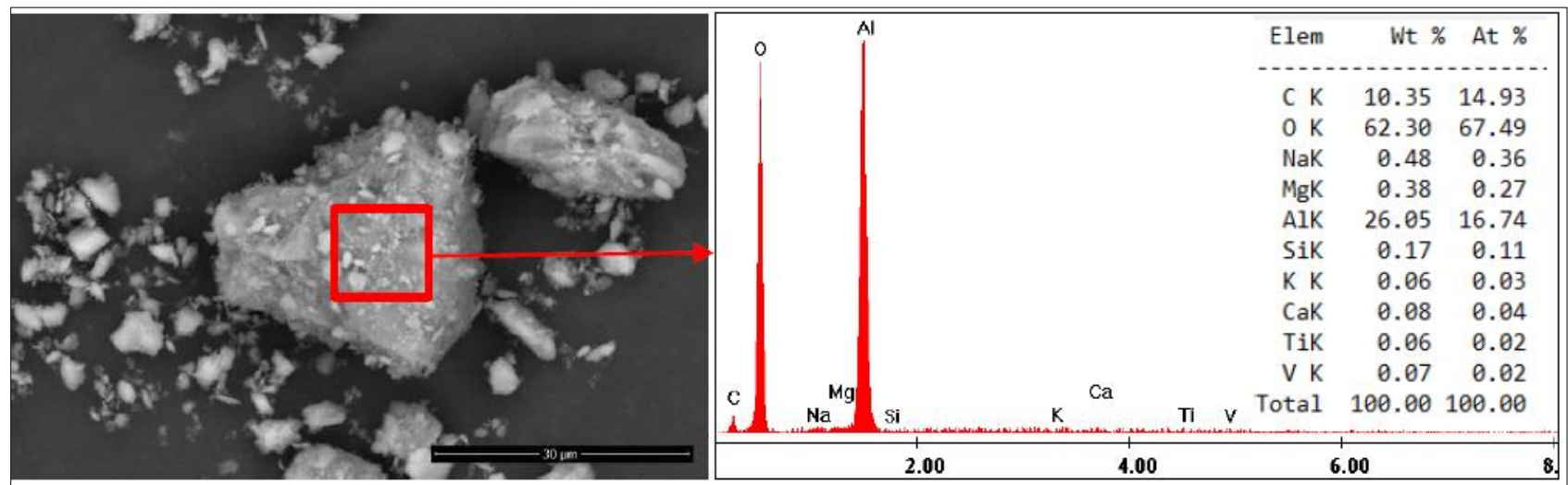

Figure 13. Morphology of an aluminum hydroxide particle, collected from dried and classified product, investigated by diffraction EDS on a surface of $10 \mu \mathrm{m}^{2}$ and magnification 5000x. SEM image of a well gibbsite particle from PSD class bellow $5 \mu \mathrm{m}$, with multiple occlusions with small fragments from complex impurity phases originated from bauxite residue (sodalite, cancrinite, $\mathrm{TiO}_{2}$ compounds) and contaminated with ionic $\mathrm{K}, \mathrm{Mg}$ and $\mathrm{V}$

Highlighting the sources and mechanism of impurities occlusion, we have got enough knowlege and competence to find engineering solution abatement of these embarrassing problems with negative effect 
on the quality of aluminum hydroxide. Actually, in the last years there were developed many researches for improving quality of the aluminum hydroxide and for raising the sodium aluminates decomposition process performances [13]. By now, we are seeing more clearly the process stages where we have to act simultaneously with effective measures for preventing the impurities occlusion. But, the process control parameters should be permanently monitored, because the contamination mechanism, also, includes auto-generation steps of the contamination sources, due to the large and frequent fluctuations in supersaturation along the aluminates decomposition line. Al the experimental data are in good agreement with published literature on this subject [7-12].

Thus, the obliterating the contamination sources means a fine evaluation and a good control over four parameters that keep away the typical impurities from concentrated or diluted Bayer fluids: a) The purity of bauxite and the possibility of removal of certain categories of impurities directly in the preparation phase of bauxite, as a raw material (separation of reactive silica and even quartz as nonreactive silicon, advanced washing for the elimination of organic substances, etc.); b) The efficient control over crystallization of all newly formed mineralogical phases during the digestion of bauxite, the advanced decantation of bauxite residue (sodalite, cancrinite, katoite, all calcium and magnesium salts, etc.), and growth prevention of the polycrystalline agglomerates between these phases; c) The efficient control in the red filtration process by optimizing the equipment parameters and by raising the quality of TCA as a filter layer for sodium aluminates super-concentrated solutions; c) The efficient control in the red filtration process by optimizing the equipments and equipments, and by raising the quality of TCA as a filter layer for sodium aluminates super-concentrated solutions; d) The best control of supersaturation in each vessel on the sodium aluminates decomposition line.

\section{Conclusions}

There are four groups of impurities soluble or insoluble in the concentrated Bayer liquors. All of them are mobile and can trigger, theoretically, the contamination by occlusion at any crystallization wessel from the sodium aluminates decomposition line:

- Ionic impurities originating from recycled Bayer liquors, where they are accumulating continuously, and could be found in all fraction of aluminum hydroxide. Sodium free ion as sodium hydroxide appears very often following a mechanism which accepts the incorporation of this ion in aluminum hydroxide lattice displacing aluminum ions. Potassium and even magnesium can follow the same route for occlusion. In the Figures 12 and 13 are very clearly illustrating this mechanism of contamination.

- Insoluble inorganic products originating from raw materials (bauxite, slaked lime, others) are common particles in Bayer liquors. They can trigger very easily the contamination by hetero-nucleation at low supra-saturation in Bayer liquors.

Sometimes in very cloudy liquors, this mechanism of occlusion could be predominant in aluminum hydroxide contamination by occlusion. Figure 11 is a very interesting example, in which a minute crystal of quartz was enough for building up a large agglomerated particle.

- Fragments of well-defined mineralogical phases originating, mainly from new born mineralogical phases in Bayer process are the typical models of real occlusions of the aluminum hydroxide. Figure 13 is a good example illustrating the result of an occlusion originating from large and complex particles born during Bayer reactions (Figures 7 and 9). This type occlusions are not meet very often, because always there are applied measures to prevent the access of these particle in sodium aluminates decomposition line.

- Soluble and insoluble organic substances originating from Bayer liquors, where they are accumulating continuously, are usual contaminants in aluminum hydroxide. Thus, it was observed that in all cases of occlusion examined, the carbon is ubiquitous. Mainly, the presence of inorganic carbon as alkaline and alkaline-earth carbonates is perfectly justified by the fact that lime is a secondary raw material of undeniable importance in Bayer technology. And, as a result, particulate carbon as carbonate might be participating as occluded impurity in aluminum hydroxide. Bauxite organic substances are 
extracted and converted by the sodium hydroxide in hundreds of compounds and with various functional groups in the molecule. Some of the organic compounds, especially those with cyclic chains in the molecule, are soluble in Bayer liquors and never reach the bauxite residue as distinct particles, nor can they be occluded in aluminum hydroxide particles. As a result, these compounds may participate in the formation of aggregates from aluminum hydroxide particles, but only as surface impurities. Organic compounds with aliphatic chains in the molecule usually form soluble sodium salts, which have limited solubility in Bayer liquors. As a result, these compounds may participate in the formation of aggregates from aluminum hydroxide particles, both as surface impurities and as occlusion impurities. This last case is well illustrated in Figure 7 and 13.

Al the above data are in good agreement with the published literature in domain of Bayer alumina production.

Acknowledgments: This study was possible by implementation of the "Endow the Research and Development Department of SC ALUM SA Tulcea with independent and efficient research facilities to support the economic competitiveness and business development" project, co-funded by the European Regional Development Fund through the Competitiveness Operational Programme 2014 - 2020. Under this project were purchased and commissioned: "Independent equipment/Installation for research and development of the technology of wet aluminum hydroxide classification", "Independent equipment/ Installation for research and development of technology to obtain the dried aluminium hydroxide" and "Independent equipment/Installation for research and development of the technology of grinding and screening the dried aluminum hydroxide". Also, this work was supported from the research grant BC 13 / 14.02.2020 - University Polytechnica Timisoara.

\section{References}

1. WATLING, H.R., FLEMING, W. VAN BRONSWIJK S.D., ROHL, A.L., J. Am. Chem. Soc Dalton Trans., 18, 1998, p.3911.

2. EREMIN, N.I., CHEREPANOVA, M.I., SHMORGUNENKO, N.S., MAKSAKOVA, M.A., Soviet Non-ferrous Metals Research, 8, 1980, 132.

3.EREMIN, N.I., CHEREPANOVA, M.I., MAKSAKOVA, M.A., Soviet Non-ferrous Metals Research, 8, 1980, p.263.

4. CLERIN P., CRISTOL, B., Light Metals, 1998, p. 141.

5. DOBRA, G., BADILITA, V., ILIEV, S., COTET., FILIPESCU., L., BOIANGIU, A., U.P.B. Sci. Bull. Series B, 81, no. 3, 2019, p. 163.

6. DOBRA, G., ILIEV, S., ANGHELOVICI, N., COTET., L, FILIPESCU., L., Rev. Chim. 70(2), 2019, 355.

7. GROCOTT, S.C., ROSENBERG, S.P., Proceedings of the International Alumina Quality Workshop (Gladstone, QLD). 1988, p. +271.

8. SANG, J.V., Light Metals, 1988, p. 147.

9. ARMSTRONG, L, Proceedings of the $3{ }^{\text {rd }}$ International Alumina Quality Workshop, 1993, p. 282.

10. ARMSTRONG, L. HUNTER, J., MCCORMICK K., WARREN, H., Light Metals, 1996, p. 37.

11. VERNON, C.F., BROWN, M.J., LAU D., ZIEBA, M.P., Proceedings of the $6^{\text {th }}$ International Alumina Quality Workshop (Brisbane, Australia), 2002, p. 33.

12. VERNON, C.F., LOH, J., LAU, D., STANLEY, A., Light Metals 2005, 602.

13. LIU, G.H., WANG, P., QI, T.G., LI, H.B., TIAN, L., ZHOU, Q.H., PENG, Z.H., Trans. Nonferrous Met. Soc. China 24, 2014, p.243.

$\overline{\text { Manuscript received: } 25.08 .2020}$ 